\title{
O PARADOXO DA PROFISSIONALIZAÇÃO DO FUTSAL FEMININO NO BRASIL: ENTRE O ESPORTE E OUTRA CARREIRA ${ }^{1}$
}

\author{
Ana Claudia Ferreira de Souza \\ Instituto Federal de Educação, Ciência e Tecnologia do Sul de Minas Gerais, Muzambinho, Minas \\ Gerais, Brasil \\ Mariana Zuaneti Martins \\ Universidade Federal do Espírito Santo, Vitória, Espírito Santo, Brasil
}

\begin{abstract}
Resumo
Este artigo descreve o perfil das atletas e o contexto do futsal feminino, analisando a relação entre o perfil socioeconômico, a formação esportiva e a carreira esportiva destas jogadoras no estado de São Paulo. Para tanto, aplicamos um questionário misto para 87 atletas, abarcando todas as que disputaram o campeonato paulista de 2015. Nossos resultados apontam que a carreira no futsal de mulheres é pouco estruturada, o que ajuda a compreender o motivo pelo qual o perfil das atletas é formado por mulheres de famílias de baixo capital cultural e poder aquisitivo. Para elas, a carreira no futsal constitui um paradoxo, pois não é um projeto de vida em si, mas a fonte de acesso a outro, que pode se consolidar como uma possibilidade de mudança social para elas.
\end{abstract}

Palavras-chave: Futsal. Mulheres. Carreira esportiva.

\section{Introdução}

A análise da formação e da carreira esportiva possibilita a compreensão dos elementos que predominam na conformação da trajetória de um atleta de elite de uma determinada modalidade esportiva. A questão pode ser abordada por diversos ângulos, por exemplo, com base nos aspectos morfológicos, técnico-táticos ou sociais e culturais. Este artigo trata deste último ângulo, enfocando o processo de formação esportiva que constitui a carreira da atleta de futsal feminino de alto rendimento do estado de São Paulo.

O conceito de carreira esportiva de um atleta é entendido como "uma atividade esportiva desenvolvida em muitos anos, escolhida voluntariamente por uma pessoa e voltada para atingir seu pico de performance atlético em uma ou diversas modalidades esportivas" (STAMBULOVA et al., 2009, p. 39). Esta concepção foi desenvolvida tendo em vista a importância de enfatizar alguns aspectos sociais e culturais até então não valorizados, como a escolha individual para tornar-se atleta, o compromisso de muitos anos para isso acontecer e a possibilidade também de se especializar em mais de um esporte ao longo da carreira (BLO$\mathrm{OM}$ et al., 1985). Esse enfoque, por conseguinte, trata da carreira considerando seus diferentes estágios: iniciação diversificada; desenvolvimento e especialização; aperfeiçoamento e

\footnotetext{
${ }^{1}$ Agradecemos à FAPEMIG pelo financiamento desta pesquisa.
} 
anos de investimento; final e anos de manutenção do desempenho; e, por fim, anos de destreinamento e descontinuidade do envolvimento competitivo. Este artigo enfocará os estágios de iniciação, especialização e investimento na carreira de elite no futsal feminino.

O futsal é uma das modalidades esportivas coletivas mais populares e praticadas pelos brasileiros (SANTANA, 2008). De acordo com o autor, a sua semelhança com o futebol ${ }^{2}$ faz com que a modalidade seja muito popular no Brasil e que seja um dos esportes mais praticados nas aulas de Educação Física e nos espaços de educação não formais do país. Além disso, constituem-se ligas e federações espalhadas por todos os estados brasileiros.

No Brasil, tanto o futebol quanto o futsal são esportes generificados, isto é, sua estrutura e valores "refletem concepções dominantes de masculinidade e feminilidade, de modo que contribuem para a solidificação da ordem de gênero corrente" (MESSNER, 1992 apud SOUZA; ALTMANN, 1999, p. 58). Compreende-se gênero como um marcador exclusivamente social que conforma identidades distintas entre homens e mulheres (SCOTT, 1995). De acordo com Scott (1995, p. 75), o gênero se configura como "uma categoria social imposta sobre um corpo sexuado". Por isso, ao estudar a carreira esportiva de mulheres, em especial no futsal, é importante que se tenha em vista o papel do marcador de gênero na sua constituição.

Quando as mulheres se inserem na prática do futsal ou do futebol enfrentam resistência, invisibilidade e até mesmo proibições formais, como em meados do século XX no Brasil (GOELLNER, 2006). Quando nos referimos ao futebol, notamos um contraste enorme a respeito das condições e possibilidades de prática, de permanência e de profissionalização entre homens e mulheres (SOUZA JUNIOR, 2013). Embora a legislação obrigue o futebol a ser um esporte profissional, essa possibilidade hoje só é garantida aos homens, permanecendo as mulheres imersas em um amadorismo, cenário no qual as atletas não recebem salários e apenas em algumas equipes obtêm ajuda de custo para o transporte ou ainda vínculo por meio de bolsa com instituições de ensino superior. A consequência é que as atletas são forçadas a trabalhar remuneradamente em outras ocupações, de modo que não conseguem se dedicar integralmente à modalidade, o que pode gerar queda de qualidade técnica das competições, desistência da prática ou a ida ao exterior por parte das atletas, como relatado por Souza Junior (2013) e Marchi Júnior, Ferreira e Salvini (2014).

No caso do futsal, o Brasil diferencia-se dos demais países da América do Sul por apresentar uma melhor estrutura na modalidade feminina de alto rendimento (ALTMANN; REIS, 2013). Considerando este contexto, nossa pesquisa buscou mostrar os processos e os percursos formativos esportivos das atletas que chegam ao alto rendimento, de modo a contemplar questões sobre a iniciação, a especialização na modalidade e a constituição do vínculo federativo e sua profissionalização.

Por isso, o presente trabalho teve como objetivo descrever e analisar a relação entre o perfil socioeconômico, a formação esportiva e a carreira esportiva em jogadoras de futsal de alto rendimento do estado de São Paulo. A compreensão desse contexto se deu a partir do perfil das atletas sob a visão delas mesmas. A partir daí, buscou-se a influência da formação esportiva na constituição do contexto profissional da modalidade na categoria feminina (ARENA; BÖHME, 2004; BAYER, 1994; COELHO, 1988; CÔTÉ; LIDOR; HACKFORT, 2011; GRECO; BENDA, 1998).

\section{Percurso metodológico}

\footnotetext{
${ }^{2}$ As semelhanças dizem respeito ao fato de ser uma modalidade esportiva coletiva de invasão, jogada com os pés (BAYER, 1994; GARGANTA; PINTO, 1995), e em quadras, requerendo assim um número de jogadores e um espaço menor.
} 
Esta pesquisa analisou o perfil de 87 atletas mulheres do futsal paulista. O intuito foi de que esse perfil fosse capaz de identificar o contexto do alto rendimento da modalidade, que, por sua vez, reflete as condições de iniciação e especialização. O perfil que consideramos é o socioeconômico e de formação esportiva. Inspirado na pesquisa de Marques e Samulski (2009), que estudou o perfil socioeconômico dos atletas de futebol de campo, este estudo utilizou-se como indicativos dessa variável as seguintes informações: idade, sexo, faixa de remuneração salarial e escolaridade do atleta e de seus pais, bem como a ocupação deles.

Além disso, incorporamos ao perfil socioeconômico informações sobre a iniciação e a especialização esportiva. Tal escolha se deu por dois motivos: (I) até então, não existem pesquisas que integram esses dois dados; (II) essa integração nos possibilita compreender a relação das características do alto rendimento com o ambiente pedagógico da iniciação e especialização esportiva. Estas informações integradas caracterizaram o contexto atual do futsal feminino no estado de São Paulo ${ }^{3}$. A escolha do caso paulista se refere ao fato de ser um dos que podem ser considerados com a mais extrema profissionalização do futsal feminino no Brasil (GERRING, 2007). Isso significa que a análise deste caso específico, ao exagerar nas proporções da profissionalização do futsal, visto que se detém em um dos estados em que ela é mais acentuada, permite conhecer mais delineadamente o contexto que gera a excelência dessa modalidade no país.

O nosso banco de dados foi formado pela população das atletas de futsal que disputaram o Campeonato Paulista em 2015 na categoria adulto feminino e se dispuseram a responder a um questionário misto, composto de questões abertas e fechadas ${ }^{4}$. Este instrumento possibilitou coletar informações de um volume grande de interlocutores e sistematizá-las, procedimento este necessário para a elaboração de algumas generalizações (BABBIE, 1999). O fato de todas as atletas dispostas a participar da pesquisa terem respondido a este questionário nos fez não necessitar de uma amostra, o que nos conferiu uma vantagem estatística no que diz respeito à inferência dos resultados (MORETTIN; BUSSAB, 2004) ${ }^{5}$.

A análise de dados foi realizada por meio da estatística descritiva, a partir do cálculo de medidas resumo de cada um dos índices analisados. Segundo Morettin e Bussab (2004, p. 35 ), estas medidas nos auxiliam por gerar "um ou alguns valores que sejam representativos da série toda". Com isso, temos uma informação que representa toda a população, que facilita

\footnotetext{
${ }^{3}$ Uma das maiores federações estaduais do país é a Federação Paulista de Futsal (FPFS), que organiza os campeonatos femininos nas categorias sub13, sub15, sub17, sub20 e adulto, sendo competições do Estadual (Metropolitano) e Troféu Piratininga e totalizando 37 equipes disputantes em todas as categorias femininas em 2015. O futsal paulista destaca-se também pela organização e pela estrutura em realizar campeonatos na categoria feminina. Quando pesquisadas as federações de futsal de Santa Catarina, Rio Grande do Sul, Paraná, Minas Gerais e Rio de Janeiro, notou-se que, mesmo sendo entidades antigas e muito atuantes no Brasil, estas federações, em geral, organizam apenas um campeonato adulto da modalidade por ano, sem categorias de base.
}

${ }^{4}$ Do ponto de vista dos aspectos éticos da pesquisa, as atletas eram abordadas em treinos ou após os jogos. Era sempre solicitada a autorização ao responsável da equipe, os objetivos eram explicados, assim como era deixado claro o anonimato das entrevistadas. Sempre junto ao questionário, era entregue às atletas o Termo de Consentimento Livre e Esclarecido (TCLE). A pesquisa em questão foi aprovada pelo Comitê de Ética em Pesquisa (CEP), do Instituto Federal de Educação, Ciência e Tecnologia do Sudeste de Minas Gerais (IF SUDESTE-MG) (CAAE número 53435816.8.0000.5588).

\footnotetext{
${ }^{5}$ Pode-se estimar, com base na edição passada da competição investigada, que participaram oito times femininos, com cerca de 112 atletas no feminino. Essa estimativa foi feita multiplicando o número de equipes por 14, que é o número de atletas que podem ser relacionadas em cada partida. Porém, cabe ressaltar que nem todas as equipes contam com 14 atletas e que todas as que estavam no local da pesquisa no dia em que foi aplicado o questionário foram convidadas e responderam ao questionário.
} 
comparar as medidas. Além disso, as medidas resumos permitiram comparar os nossos dados de iniciação e especialização com o previsto pela literatura acadêmica.

\section{Perfis, formação esportiva e profissionalização das atletas paulistas de futsal}

\section{Perfil socioeconômico das atletas, profissionalização e carreira dual}

Refletindo sobre a importância dos aspectos social e econômico em relação à prática esportiva das atletas, considera-se ser importante uma análise sobre o ambiente em que se dá essa prática, acreditando que estes aspectos influenciam nas questões de jogos. O desenvolvimento das competências no esporte que possibilitam o acesso ao alto rendimento depende do processo de treinamento e do ambiente, tanto quanto as questões sociais (CÔTÉ, 1999). Segundo Marques e Samulski (2009, p. 104), o estudo desses elementos pode ser de fundamental importância para o "aconselhamento junto a atletas, pais de atletas, empresários, treinadores e dirigentes esportivos, pois possibilitam um maior entendimento dos processos organizacionais, sociais e psicológicos que permeiam a trajetória esportiva de atletas".

$\mathrm{O}$ grupo pesquisado é de atletas que chegaram ao alto rendimento e jogam tanto no campeonato paulista quanto em outros campeonatos. E mesmo não tendo contrato assinado, elas se dedicam ao esporte e fazem dele uma oportunidade para construir uma carreira além do futsal. Responderam ao questionário atletas com idades entre 16 e 35 anos, com média de idade de 22,83 anos $( \pm 3,22)$, conforme demonstramos na Tabela 1. Das 87 atletas, apenas seis tinham até 18 anos, o que corresponde a 6,89\% da amostra e, consequentemente, 81 delas, ou 93,11\%, tinham idade igual ou superior a 19 anos, sendo consideradas adultas, segundo o Estatuto da Criança e Adolescente (ECA). Martins (2013), ao descrever o contexto de Minas Gerais, notou que apesar do fato de a competição adulta permitir a participação de maiores de 16 anos, cerca de 43,75\% eram adolescentes. Já em São Paulo, onde o regulamento estipula que a idade mínima para participar é de 15 anos, o percentual de atletas adultas é bem alto, o que pode caracterizar uma profissionalização da modalidade dentro do estado, uma vez que são poucas as atletas adolescentes na categoria principal.

Tabela 1. Medidas Resumo da Idade das Atletas

\begin{tabular}{lr}
\hline $\mathbf{N}$ & $\mathbf{8 6}$ \\
\hline Média & 22,83 \\
Desvio Padrão & 3,22 \\
Coeficiente de Variação & 0,14 \\
Mínimo & 16 \\
$\mathbf{1}^{\circ}$ Quartil & 21 \\
Mediana & 22,50 \\
$\mathbf{3}^{\mathbf{0}}$ Quartil & 24,75 \\
Máximo & 35 \\
\hline \multicolumn{2}{c}{$\quad$ Fonte: Os autores, 2016 }
\end{tabular}

Do ponto de vista do perfil ainda, a maioria das atletas $(81,6 \%)$ está se graduando no ensino superior ou já é graduada, conforme é possível verificar no Gráfico 1. Os cursos nos quais eles se graduaram, em sua maioria, são voltados para a área da saúde. Este resultado vai ao encontro da pesquisa de Altmann e Reis (2013), que descreveram que uma das formas de remuneração das atletas é a concessão de bolsas de estudo. $O$ fato de os clubes oferecerem essas bolsas justificaria o alto percentual de atletas com ensino superior em andamento ou completo. Até mesmo as atletas que relataram ter cursado apenas ensino médio completo ou 
incompleto afirmaram que o clube oferece bolsas estudantis, caso haja o interesse em retomar os estudos.

Gráfico 1. Escolaridade das atletas e de seus pais

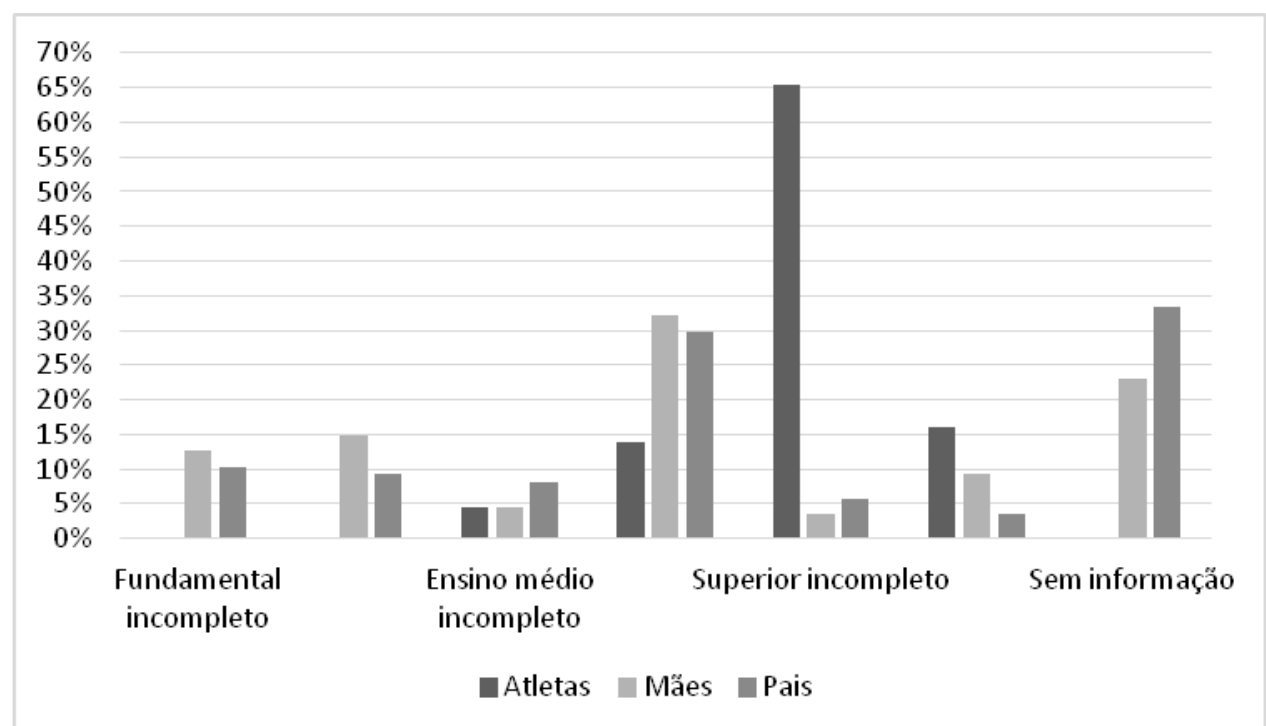

Fonte: Os autores, 2016

Essa questão é ainda mais marcante quando notamos que os pais dessas atletas, em geral, não têm formação superior. Apenas $16 \%$ das mães e $18 \%$ dos pais tiveram acesso ao ensino superior, apresentando, a maioria, baixa escolaridade. As profissões exercidas pelos pais em geral referiam-se a trabalhos manuais - como pedreiro, ajudante geral, motorista, segurança, vigilante, etc. - , muitas vezes de grande carga de esforço físico. Entre as mães, grande parte são donas de casa, vendedoras, ajudantes geral, domésticas, costureiras, etc.. Esse quadro pode caracterizar o baixo poder aquisitivo das famílias, justificado pela baixa escolaridade, bem como das profissões exercidas.

Neste sentido, o exercício do futsal de alto rendimento tem permitido a estas atletas o acesso ao ensino superior, elevando a expectativa de uma profissão com melhor remuneração futura e a possibilidade de ascensão dos níveis sociais e econômicos para estas famílias. Portanto, não só o futsal permite a construção de um projeto de vida, como este pode significar uma mudança social na estrutura familiar. Uma mudança ao menos ao que se refere ao capital cultural familiar, já que será a primeira geração de muitas famílias com nível superior.

A pesquisa de Souza Junior (2013) sobre o futebol de mulheres demonstrou que o benefício da bolsa de estudos é uma forma de remuneração frequente na modalidade. Ainda segundo o autor, essa percepção pode levar à hipótese de que essas atletas não acreditam na viabilidade de um projeto de vida firmado exclusivamente no futebol, necessitando de uma "carreira paralela", uma alternativa, que será responsável por proporcionar alguma segurança em relação ao futuro. No entanto, ao mesmo tempo em que esse dado nos demonstra uma grande diferença com relação ao futebol de homens, que podem construir um projeto de vida relacionado à modalidade, paradoxalmente, essa condição pode ser interessante. Na medida em que estas atletas também se dedicam a outra carreira, elas ficam mais preparadas para a reconversão após a carreira esportiva, fato este não presente no futebol de homens (DAMO, 2007). Além disso, do ponto de vista pedagógico, isso também faz com que as mulheres não abandonem os estudos em função do esporte, condição que é predominante no futebol de homens (SOARES et al, 2011).

Além das bolsas de estudos, são concedidos benefícios como moradia, conforme demonstramos no Gráfico 2. Em São Paulo, $86 \%$ das atletas têm alguma remuneração, sendo 
que $57 \%$ delas recebem mais que um salário mínimo, conforme é possível ver no Gráfico $3^{6}$. Notou-se que, em um grupo de atletas, 6,9\% relatou não receber remuneração do clube, por estar jogando em clubes que não tiveram uma campanha de sucesso no campeonato paulista, não conseguindo classificação para a fase seguinte, a etapa eliminatória. As equipes que compuseram o quadrangular final são os times que melhor remuneram suas atletas, e todas elas indicaram receber alguma remuneração além dos benefícios concedidos pelo clube, sendo esses salários, em sua maioria, os mais altos do estado.

Gráfico 2. Benefícios concedidos às atletas

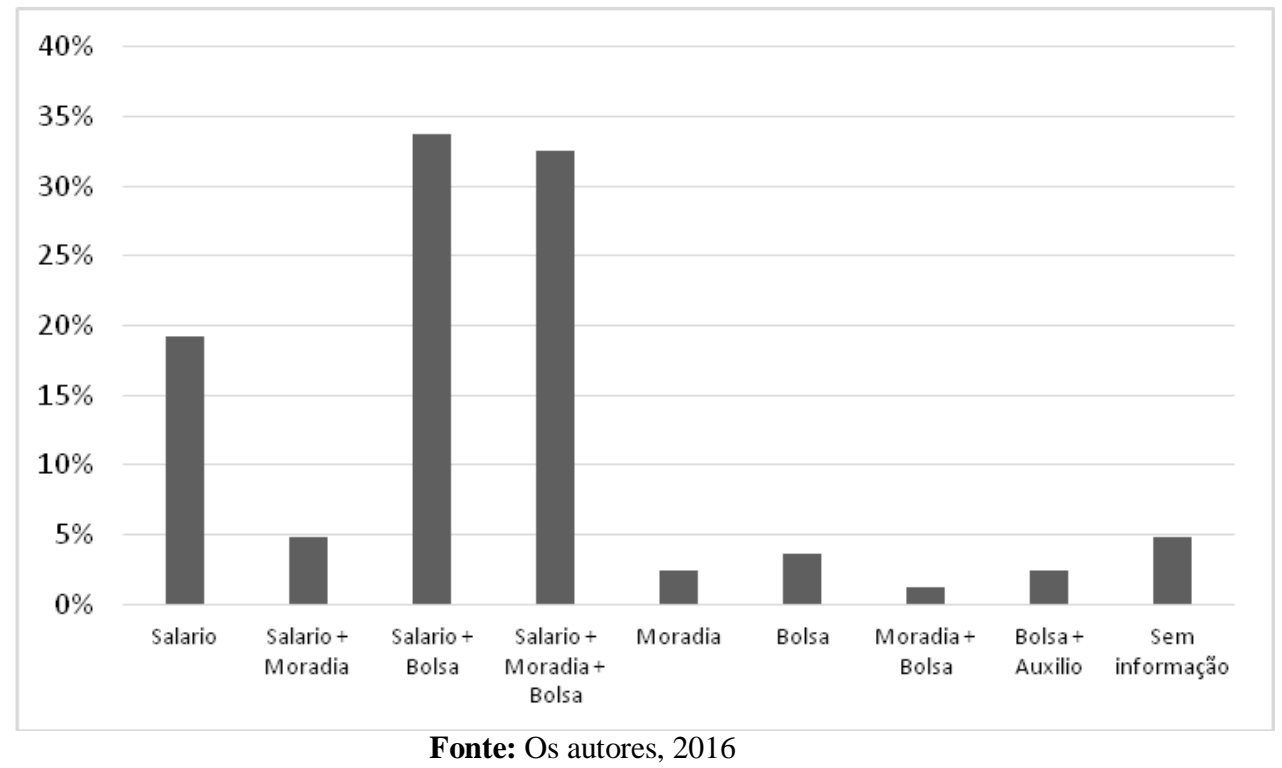

Gráfico 3. Remuneração recebida pelas atletas

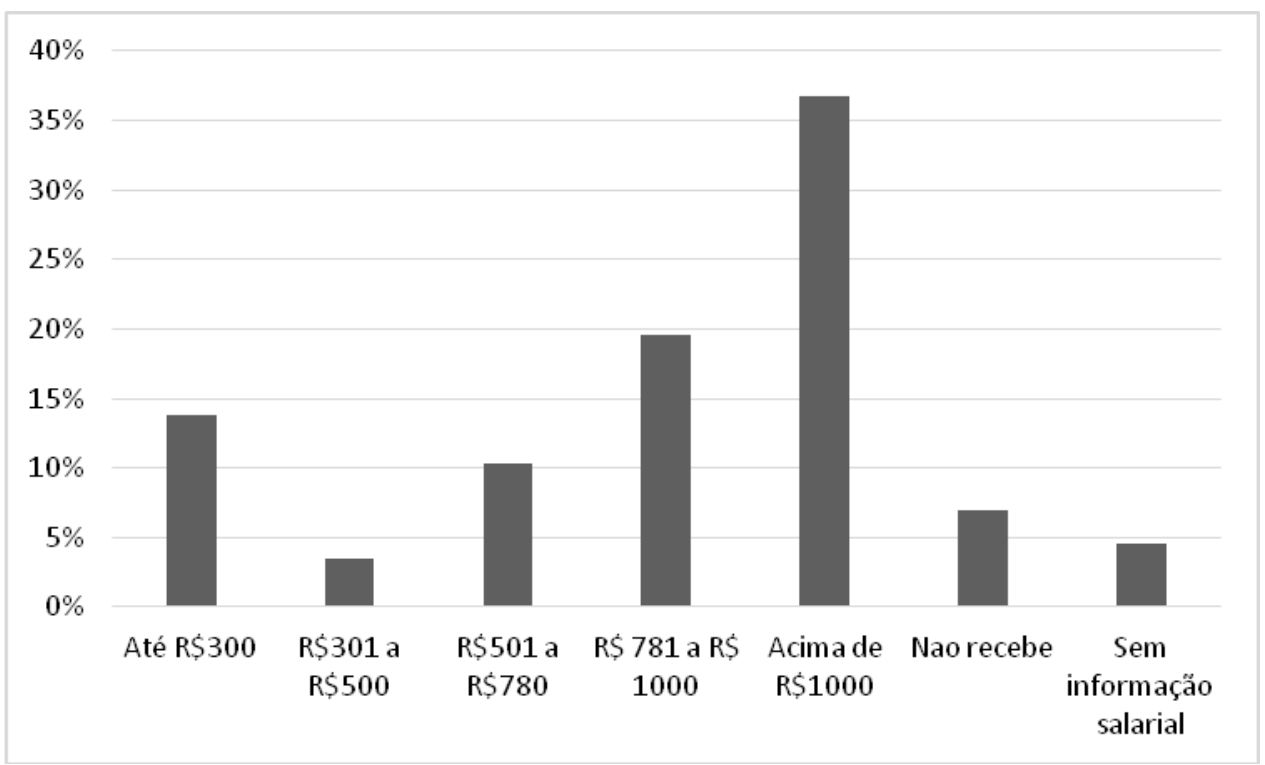

Fonte: Os autores, 2016

Portanto, considerando que as jogadoras devem cumprir horários de treinamentos, concentrações, jogos, tarefas características de um profissional do esporte, e recebem remuneração para tal, podemos classificar como uma relação de emprego disfarçada (SOUZA JÚ-

\footnotetext{
${ }^{6}$ Em 2015, um salário mínimo no Brasil correspondia a R\$ 788,00
} 
NIOR, 2013). Disfarçada, porque as atletas não contam com os demais direitos trabalhistas, como contrato de trabalho e previdência. Seus salários são complementados com benefícios, bolsa de estudos, ou ajuda de custo $^{7}$. Essa relação ainda aparece quando perguntadas sobre o vínculo profissional: quase todas as atletas relataram não ter contrato com o clube e carteira assinada como atletas. Apenas duas atletas $(2,29 \%)$ relataram ter algum tipo de contrato ou carteira assinada pelo clube. Ou seja, para a maioria, apesar de receber salário e ter benefícios, o vínculo com o clube não é oficializado. Por mais que a quase totalidade dessas atletas não tenham contrato profissional, quando perguntadas se se consideravam como profissionais do futsal, $85 \%$ delas disseram que sim.

A troca entre clubes é feita, por sua vez, por intermédio delas mesmas, direto com a equipe interessada. Apenas três atletas afirmaram ter um agente ou empresário para concretizar as transações. Segundo Souza Júnior (2013), se, por um lado, as atletas têm a liberdade de trocar de clube a qualquer momento, uma vez que não têm contrato nem vínculo com empresários, paradoxalmente, essas atletas não têm garantias legais ou segurança na carreira. Esse cenário gera instabilidade na carreira destas jogadoras, que apontam a fragilidade dos vínculos com os clubes como uma das principais preocupações que assolam sua "carreira profissional".

A consequência desse cenário, do ponto de vista da profissionalização, é que a manutenção dessa condição torna-se inviável por um prazo maior e, por isso, muitas atletas abandonam essa condição mesmo antes do fim útil de sua vida esportiva. Isso é possível de ser notado na idade das atletas, que é concentrada até a faixa dos 25 anos, que coincide com o momento da vida em que elas ainda estão cursando o nível superior de ensino. Ou seja, o futsal é uma carreira que serve enquanto elas se preparam para outra. Em outras palavras, é um paliativo para a construção de outro projeto de vida.

A partir desse panorama, podemos refletir se esse paradoxo não apresentaria questões positivas para a transição de carreira dessas atletas. Em primeiro lugar, é importante ressaltar que o conceito de carreira esportiva pode englobar sua manifestação tanto de forma amadora como profissional, dependendo do status do atleta, uma vez que mesmo atletas de elite organizam suas carreiras combinando-as com outras atividades, inclusive profissionais (STAMBULOVA et al., 2015). Esta combinação pode ser vista de forma positiva ou negativa. Negativa, porque implica, muitas vezes, uma dedicação precária à modalidade, o que resultará em um desempenho abaixo do possível. Positivo, porque pode representar uma forma menos estressante de lidar com as transições da carreira, em especial a transição para a fase final dela.

Este modelo que combina a carreira esportiva com outras atividades é conhecido como carreira dual. Ele é desenvolvido a partir da transição da categoria Junior para a Adulta e tem sido visto como promotor de benefícios nesse processo, uma vez que ajuda a balancear o estilo de vida, reduzir o estresse da competição, desenvolver habilidades em outras esferas da vida e permitir uma maior empregabilidade após o fim da carreira como atleta (PAPAIOANNOU; HACKFORT, 2014). Evidentemente que a carreira dual pode gerar uma sobrecarga de trabalho, um overtraining, aumentando o risco de lesões e ocasionando um dropout prematuro (STAMBULOVA et al., 2015). Por isso, é necessário suporte acadêmico e profissional para o desenvolvimento destas duas atividades (RYBA et al., 2015).

No futebol feminino, essa carreira dual é vista como um ônus, uma vez que a ausência de contratos de trabalhos formais e carteira assinada são um ônus para as atletas, que se reconhecem como profissionais, porém, se veem destituídas de seus direitos legítimos da profissão, demonstrando uma grande preocupação em não obter uma segurança legal com sua profissão (SOUZA JÚNIOR, 2013).

\footnotetext{
${ }^{7}$ Consideramos ajuda de custo quando a remuneração é abaixo do salário mínimo ou quando não tem uma regularidade frequente.
} 
No entanto, quando olhamos o quadro do futsal feminino, percebemos que a carreira dual predomina, uma vez que $84 \%$ delas recebem rendimentos advindos da prática esportiva, mas $81,6 \%$ já cursaram ou estão cursando o ensino superior. Nesse sentido, há uma combinação da vida de atleta com a vida acadêmica, o que, como já evidenciamos, teve um sentido positivo para estas atletas, uma vez que elas representam a primeira geração familiar delas a investir na formação de ensino superior. Isso possibilita a elas lidar de forma planejada com a transição do final da carreira, de modo a terem uma ocupação quando este momento chegar.

Perfil esportivo: condições de iniciação, especialização e investimento para o alto rendimento da modalidade neste contexto de profissionalização

Segundo Greco e Romero (2012), existem numerosos estudos a respeito de detecção de talento no esporte, mesmo sendo difícil analisar esse critério. No entanto, uma nova orientação metodológica propõe fazer análises ao contrário. Ao invés de detectar o talento, esta orientação propõe que se estude a sua formação. Isto é, de baixo para cima, como um paradigma qualitativo e focado também no ambiente em que o atleta é formado. Ela fundamentase observando o processo de formação dos atletas de elite que se destacaram em seu rendimento. Busca-se encontrar variáveis críticas que estabelecem as diferenças entre as distintas esportistas. Essa nova análise pode-se fazer, por sua vez, analisando a formação de jogadores que também têm alcançado o êxito esportivo. A partir dessas análises é possível entender o que influencia, no futsal de mulheres no Brasil, o desempenho de atletas de excelência (GALATTI et al., 2015).

Do ponto de vista da iniciação esportiva, a maioria das atletas (52\%) relata que joga há mais de 10 anos, demonstrando um extenso período de contato com o esporte, conforme demonstra o Gráfico 4.

Gráfico 4. Tempo de dedicação ao futsal ao longo da vida

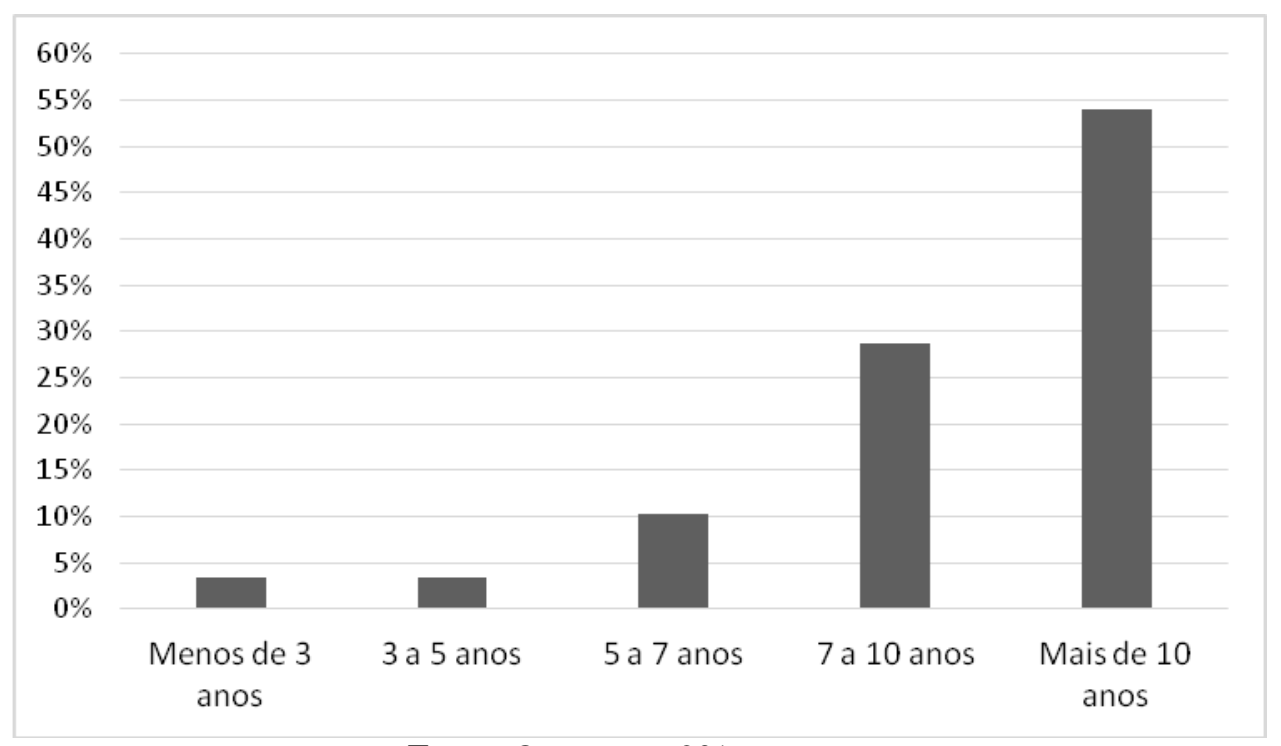

Fonte: Os autores, 2016

Além disso, $67 \%$ relataram que iniciaram no futsal jogando na rua; $17 \%$ começaram a prática na escola; $8 \%$ foram introduzidas no esporte através da prática realizada no clube e $2 \%$ conheceram a modalidade em seu condomínio, conforme o Gráfico 5. Tais dados corroboram a pesquisa de Santana e Reis (2003), que demonstrou que, no futsal feminino, a rua é o primeiro espaço de contato com a modalidade, seguido da escola. Tal aspecto levantado 13 anos 
antes da pesquisa demonstra que persiste a ineficácia ou a inexistência de clubes específicos de futsal para meninas como ambientes formadores de praticantes.

Gráfico 5. Local de início de prática de futsal

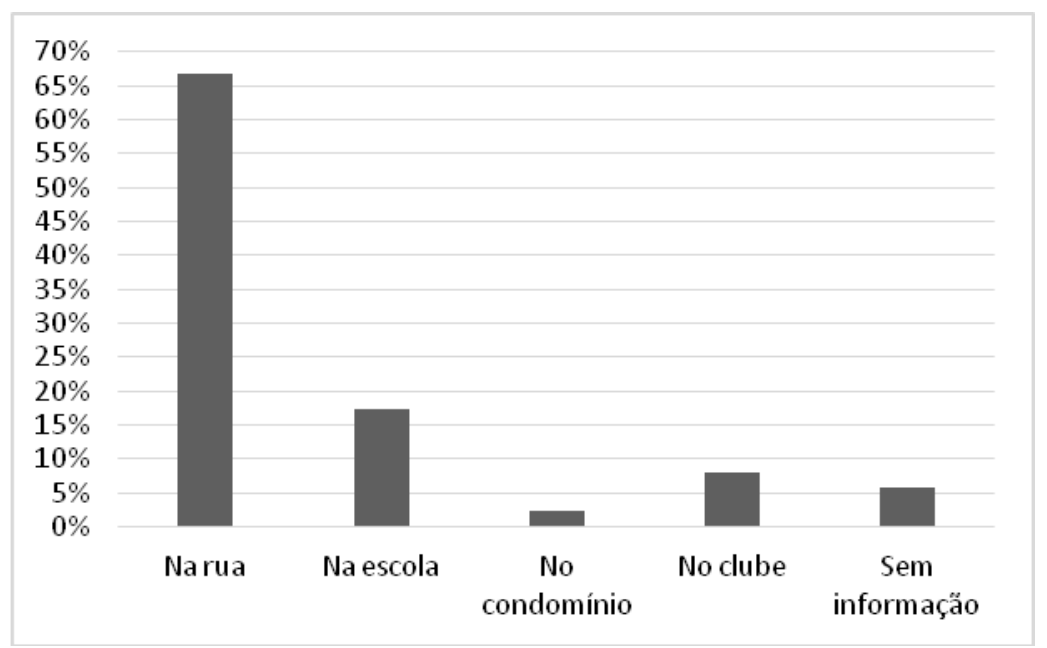

Fonte: Os autores, 2016

Dentro da escola, as aulas de Educação Física configuram-se como o principal espaço de aprendizagem e vivência do futebol. Para Greco e Romero (2012), a Educação Física é nutrida de pensadores e professores preocupados com a melhoria do seu tratamento pedagógico no contexto escolar. Considerando que o aluno não é um ser apenas biológico, mas também social e que deve ter seus limites respeitados, o modo pelo qual o futsal é ensinado na escola tem grande relevância, bem como o papel do professor, que é essencial. Ao ensinar o futsal na escola, a ideia básica é que o professor tenha conhecimentos sobre os procedimentos de ensino e escolha os mais adequados para a realidade de sua escola e de cada turma com que trabalha. Além disso, destaca-se a importância do professor de Educação Física em proporcionar oportunidades de aprendizagem de futsal igualitárias para meninos e meninas, o que possibilitaria a formação de praticantes da modalidade.

Sobre a especialização esportiva dessas atletas, elas iniciaram a prática sistemática, ou seja, treinamentos voltados à melhora do desempenho, por volta dos 11 anos, segundo a Tabela 2. A pesquisa de Martins (2013) demonstrou que, em Minas Gerais, a idade média em que as atletas foram submetidas a treinos sistematizados era de 12 anos, evidenciando que o cenário do futsal nesse estado e nesse ano era semelhante ao apontado por Santana e Reis (2003). Este cenário difere do contexto do futsal masculino, cuja idade média em que os atletas começavam com os treinos sistematizados era de nove anos (SANTANA; REIS; FRANÇA, 2008), o que alertava para o risco do início de uma prática sistemática especializada de forma precoce com os atletas, antes do recomendado pela literatura científica da área (BOMPA, 2002; CÔTÉ; LIDOR; HACKFORT, 2011).

Tabela 2. Medidas-Resumo da Idade em que as atletas começaram a treinar futsal

\begin{tabular}{cc}
\hline $\mathrm{N}$ & $\mathbf{6 0}$ \\
\hline Média & 11,32 \\
Desvio Padrão & 3,60 \\
Coeficiente de variação & 0,32 \\
Mínimo & 4 \\
\hline
\end{tabular}




\begin{tabular}{cc}
\hline $1^{\circ}$ Quartil & 9 \\
Mediana & 11,5 \\
$3^{\circ}$ Quartil & 15 \\
Máximo & 19 \\
\hline
\end{tabular}

Fonte: Os autores, 2016

No feminino, no entanto, podemos creditar à falta de competições para categorias de base no futsal paulista feminino um fator paradoxal e de alguma forma positivo nesse sentido, pois as atletas iniciariam num período adequado os treinamentos especializados. Este cenário difere bastante do masculino, no qual os atletas são federados por volta dos 12 anos (SANTANA; REIS; FRANÇA, 2006). As atletas relatam que tiveram seu primeiro vínculo em competições federadas por volta dos 15 anos, conforme Tabela $3^{8}$. Este processo pode estar em mudança pelo advento de categorias de base femininas. Segundo Arena e Böhme (2004), a existência desses campeonatos colabora para o início mais precoce na modalidade. Por isso, o fato de estas atletas constituírem vínculo federativo a partir dos 15 anos indica que elas o fizeram no momento em que já estariam numa faixa etária mais próxima ao ideal para a especialização, que Greco (1998) sugere entre 16 e 18 anos.

Tabela 3. Medidas Resumo da idade de constituição do vínculo federativo das atletas

\begin{tabular}{cc}
\hline $\mathrm{N}$ & $\mathbf{8 2}$ \\
\hline Média & 15,62 \\
Desvio Padrão & 1,93 \\
Coeficiente de Variação & 0,12 \\
Mínimo & 9 \\
$1^{\circ}$ Quartil & 15 \\
Mediana & 15,00 \\
$3^{\circ}$ Quartil & 17,00 \\
Máximo & 20 \\
\hline Fonte: Os autores, 2016
\end{tabular}

Do ponto de vista de sua especialização, nota-se que $21 \%$ das atletas se dedicam tanto ao futsal quanto ao futebol de campo de alto rendimento. São 18 atletas e 10 destas são de apenas duas equipes, enquanto as outras 8 estão distribuídas nas demais equipes citadas. Isso pode significar aos clubes uma economia em relação à contratação, ao salário e aos benefícios concedidos às jogadoras, pois não precisariam contratar atletas para as duas modalidades. Porém, isso nem sempre pode ser concreto em relação ao rendimento e ao desempenho da jogadora dentro das quatro linhas.

A prática dessas duas modalidades em alto nível simultaneamente pela mesma atleta pode significar de certa forma um prejuízo para o clube, pois, apesar de semelhantes, o futebol e o futsal apresentam características fisiológicas distintas, além de questões técnico-táticas que bloqueariam a jogadora a atingir a excelência no esporte, pois a especialização não ocorreria de fato. Buscando na literatura estudos que comparem a prática das duas modalidades no âmbito profissional, encontramos o de Nunes et al., (2012), que indicou que as variáveis fisiológicas de frequência cardíaca máxima e volume de oxigênio máximo consumido apresentaram diferenças significativas entre as modalidades, demonstrando que, no futsal, há uma demanda por uma capacidade anaeróbia mais alta que no futebol. Corroboram esse estudo Leal Júnior et al. (2006), que afirmaram que, apesar da similaridade motora entre os esportes, a

\footnotetext{
${ }^{8}$ Houve apenas uma das atletas que indicou iniciar o vínculo federativo muito nova, aos 9 anos, porém nada de diferente foi encontrado analisando os dados do seu perfil.
} 
intensidade de uma partida de futsal é mais acentuada, levando a diferenças significativas entre as características fisiológicas de atletas de futsal e futebol. Essas discrepâncias apresentadas demonstram a necessidade de diferentes ambientes de treinamento, em especial nos anos de investimento no alto rendimento nas modalidades.

\title{
Considerações finais
}

Este artigo objetivou informar sobre esse contexto do futsal no estado de São Paulo, por meio de um panorama do futsal feminino de alto rendimento e apontando as suas implicações para a formação e a profissionalização das atletas. $O$ escopo abarcado nesta pesquisa apresenta algumas limitações, na medida em que enfocou os aspectos sociais e culturais, deixando de lado os aspectos técnico-táticos que são igualmente importantes para explicar o processo de formação de um atleta de elite.

Neste artigo, descrevemos o perfil das atletas, a fim de compreender como o contexto formativo do futsal tem selecionado atletas para se profissionalizar. Este perfil demonstra as dificuldades, as limitações, as fragilidades e as potencialidades da expansão da modalidade no país. Pode-se assim indicar apontamentos, à luz da discussão acadêmica da pedagogia do esporte, para a sua melhoria. A ausência de categorias de base para o futsal feminino no país na formação dos atletas ainda é uma questão presente. Além disso, o fato de as atletas não se dedicarem exclusivamente ao futsal, praticando futebol de campo também, pode afetar o seu desempenho máximo.

Quando comparamos o perfil das atletas, sua formação esportiva e o contexto da profissionalização da modalidade, percebemos que a conformação do futsal como profissão para mulheres ainda é bastante precária, o que poderia explicar o motivo pelo qual o perfil das atletas é formado por mulheres de famílias de baixo capital cultural e poder aquisitivo. Para as mulheres dessa origem social, o futsal se apresenta como uma possibilidade de mudança social, já que é a partir dele que vão conseguir acesso ao ensino superior, o que conforma um paradoxo, já que a profissão de futsal contribui para a mudança social destas meninas, na medida em que possibilita a formação superior para outra profissão melhor que o próprio futsal.

\section{THE PARADOX OF THE PROFISSIONALIZATION OF FEMALE FUTSAL IN BRAZIL: BETWEEN SPORT AND ANOTHER CAREER}

\begin{abstract}
This article aimed to describe the profile of the athletes and the context of women futsal players and analyzed the relationship between the socioeconomic profile, the sports training and the athletic career of these players in the state of São Paulo. To achieve this, we applied a survey to all 87 futsal players, who competed in the São Paulo championship of 2015. Our results showed that the career in women's futsal is poorly structured, which points out the reason why the profile of athletes is directed to those of families with low cultural capital and purchasing power. For those women, the career in futsal is a paradox, because it is not a project of life in itself, but the way to access another one, which can be consolidated as a possibility of social change for them.
\end{abstract}

Keywords: Futsal.Women. Athletic career.

\section{LA PARADOJA DE LA PROFESIONALIZACION DEL FUTSAL DE SALA FEME- NINO EN BRASIL: ENTRE EL DEPORTE Y OTRA PROFESIÓN}

\section{Resumen}


En este artículo se describe el perfil de las atletas y el contexto del futsal femenino, analizando la relación entre el perfil socioeconómico, la formación en el deporte y la carrera atlética de esas jugadoras en la ciudad de São Paulo. Para eso, aplicamos un cuestionario mixto a 87 atletas, englobando a todas las que compitieron en el campeonato Paulista de 2015. Nuestros resultados indican que la carrera del futsal femenino es poco estructurada, lo que ayuda a entender por qué el perfil de las atletas está formado por mujeres provenientes de las familias de bajos capital cultural y poder adquisitivo. Para ellas, la carrera del futsal está constituida por una paradoja, ya que no es un proyecto de vida en sí, sino la fuente de acceso a otro, que puede consolidarse como una posibilidad de transformación social para ellas.

Palabras clave: Futsal. Mujeres. Carrera deportiva.

\section{Referências}

ALFERMANN, D.; STAMBULOVA, N. Career transitions and career termination. In: TENENBAUM, G.; EKLUND, R. C. Handbook of sport psychology. Hoboken: John Wiley \& Sons, 2007. p. 712-733.

ALTMANN, H.; REIS, H. H. B. DOS. Futsal feminino na América do Sul: trajetórias de enfrentamento e de conquistas. Movimento (ESEFID/UFRGS), v. 19, n. 3, p. 211-232, 25 abr. 2013.

ARENA, S. S.; BÖHME, M. T. S. Federações esportivas e organização de competições para jovens. Revista Brasileira de Ciência e Movimento, v. 12, n. 4, p. 45-50, dez. 2004.

BABBIE, E. Métodos de pesquisa de survey. Belo Horizonte: Editora UFMG, 1999. 519 p.

BAYER, C. O ensino dos desportos colectivos. Lisboa: Dinalivro, 1994.

BOMPA, T. Treinamento total para jovens campeões. São Paulo: Manole, 2002.

COELHO, O. Pedagogia do desporto. Lisboa: Livros Horizonte, 1988.

CÔTÉ, J. The influence of the family in the development of talent in sport. The Sport Psychologist, 13(4), 395-417, 1999.

CÔTÉ, J.; LIDOR, R.; HACKFORT, D. ISSP position stand: to sample or to specialize? Seven postulates about youth sport activities that lead to continued participation and elite performance. International Journal of Sport and Exercise Psychology, v. 1, n. 7, p. 7-17, 2011.

DAMO, A. Do dom à profissão: a formação de futebolistas no Brasil e na França. São Paulo: Hucitec, 2007.

GALATTI, L. R.; PAES, R.R.; MACHADO, G.V.; GONÇALVES, C.B.; SEOANE, A.M.. Determinantes de excelência no basquetebol feminino: as conquistas da seleção brasileira na perspectiva das atletas. Journal of Physical Education, v. 26, n. 4, p. 621-632, 25 out. 2015.

GARGANTA, J.; PINTO, J. O ensino de futebol. In: GRAÇA, A.; OLIVEIRA, J. (Ed.). O ensino dos jogos desportivos. Porto: Centro de Estudos dos Jogos Desportivos e de Educação Física; Universidade do Porto, 1995. p. 95-137. 
GERRING, J. Case study research. Nova York: Cambridge University Press, 2007.

GOELLNER, S. V. A educação dos corpos, dos gêneros e das sexualidades e o reconhecimento da diversidade. Cadernos de Formação RBCE, v. 1, n. 2, 2010.

GOELLNER, S. V. Mulher e esporte no Brasil: entre incentivos e interdições elas fazem história. Pensar a Prática, v. 8, n. 1, p. 85-100, 15 nov. 2006.

GRECO, P. J. Iniciação esportiva universal. Belo Horizonte: Universitária - UFMG, 1998. (Volume 2: Metodologia da iniciação esportiva na escola e no clube).

GRECO, P. J.; BENDA, R. N. Iniciação esportiva universal. Belo Horizonte: Universitária UFMG, 1998. (Volume 1: Da aprendizagem motora ao treinamento técnico).

GRECO, P. J.; ROMERO, J. J. F. Manual de handebol: da iniciação ao alto nível. São Paulo: Phorte, 2012.

LEAL JUNIOR, E. C. P.; SOUZA, F.B; MAGINI, M,; MARTINS, R.A.B.L. Estudo comparativo do consumo de oxigênio e limiar anaeróbio em um teste de esforço progressivo entre atletas profissionais de futebol e futsal. Revista Brasileira de Medicina do Esporte, v. 12, n. 6, p. 323-326, dez. 2006.

MARCHI JÚNIOR, W.; SALVINI, L.; FERREIRA, A.L.P.. O futebol feminino no campo acadêmico brasileiro: mapeamento de teses e dissertações (1990-2010). Pensar a prática, v. 17, n. 4, p. 1-14, 2014.

MARQUES, M. P.; SAMULSKI, D. M. Análise da carreira esportiva de jovens atletas de futebol na transição da fase amadora para a fase profissional: escolaridade, iniciação, contexto sócio-familiar e planejamento da carreira. Revista Brasileira de Educação Física e Esporte, v. 23, n. 2, p. 103-119, 1 jun. 2009.

MARTINS, L. N. Futsal feminino: perfil das atletas nos Jogos de Minas 2012 e implicações pedagógicas. RBFF - Revista Brasileira de Futsal e Futebol, v. 5, n. 18, 8 set. 2013.

MORETTIN, P. A.; BUSSAB, W. DE O. Estatística básica. 5. ed. São Paulo: Saraiva, 2004.

NUNES, R. F. H.; ALMEIDA, F.A.M; SANTOS, B.V.; ALMEIDA, F. D. M; NOGAS, G; ELSANGEDY, H.M.; KRINSKI, K. Comparação de indicadores físicos e fisiológicos entre atletas profissionais de futsal e futebol. Motriz: Revista de Educação Física, v. 18, n. 1, p. 104-112, mar. 2012.

PAPAIOANNOU, A. G.; HACKFORT, D. Routledge companion to sportand exercise psychology: global perspectives and fundamental concepts. London: Routledge, 2014

RYBA, T. V.; STAMBULOVA, N. B.; RONKAINEN, N. J.; BUNDGAARD, J.; SELÄNNE, H. Dual career pathways of transnational athletes. Psychology of Sport and Exercise, Dual Career Development and Transitions, v. 21, p. 125-134, 2015.

SANTANA, W. C. DE. Futsal: apontamentos pedagógicos na iniciação e na especialização. 2. ed. Campinas: Autores Associados, 2008. v. 1 
SANTANA, W. C. DE; REIS, H. H. B. DOS. Futsal feminino: perfil e implicações pedagógicas. Revista Brasileira de Ciência e Movimento, v. 11, n. 4, p. 45-50, dez. 2003.

SANTANA, W. C. DE; REIS, H. H. B. DOS; RIBEIRO, D. A. A iniciação de jogadores de futsal com participação na Seleção Brasileira. Lecturas Educación Física y Deportes, Buenos Aires. v. 11, n. 96, p. 1-8, maio 2006.

SANTANA, W. C.; FRANÇA, V. S.; REIS, H. H. B. Perfil do processo de iniciação ao futsal de jogadores juvenis paranaenses. Motriz. Journal of Physical Education. UNESP, v. 13, n. 3, p. 181-187, 2 jan. 2008.

SCOTT, Joan. Gênero: uma categoria útil de análise histórica. Educação e Realidade, 20 (2), p.71-99, 1995.

SOARES, G. J. A. ; ROCHA, H. P. A. ; BARTHOLO, T. L. ; MELO, L. B. S. Jovens esportistas: profissionalização no futebol e a formação na escola. Motriz, Rio Claro, v.17, n.2, p.252-263, abr./jun. 2011

SOUSA, E. S.; ALTMANN, H. Meninos e meninas: expectativas corporais e implicações na educação física escolar. Cadernos CEDES, v. 19, n. 48, p. 52-68, 1999.

SOUZA JÚNIOR, O. M. DE. Futebol como projeto profissional de mulheres : interpretações da busca pela legitimidade. 2013. Tese (Doutorado) - Universidade Estadual de Campinas, Campinas, 2013.

STAMBULOVA, N. et al. Career development and transitions of athletes. International Journal of Sport and Exercise Psychology, Northumria, v. 7, p. 395-412, 2009.

STAMBULOVA, N. et al. Searching for an optimal balance: dual career experiences of Swedish adolescent athletes. Psycology of sport and exercise, 21, p. 4-14, 2105.

STAMBULOVA, N.; WYLLEMAN, P. Athletes'career development transitions. In: PAPAIOANNOU, A; HACKFORT, D. (Ed.). Routledge companion to sport and exercise psycology. London/New York: Routledge, 2014. p. 605-621.

Recebido em: 24/01/2017

Revisado em: 18/09/2017

Aprovado em: 20/09/2017

Endereço para correspondência:

marianazuaneti@gmail.com

Mariana Zuaneti Martins

Universidade Federal do Espírito Santo, Centro de Educação Física e Desportos.

Goiabeiras

29075-910 - Vitória, ES - Brasil 